Dovey, K. \& Pafka, E. (2014)

'The Urban Density Assemblage',

Urban Design International, 19 (1): 66-76.

\title{
THE URBAN DENSITY ASSEMBLAGE: Modeling multiple measures
}

\author{
Kim Dovey \& Elek Pafka \\ Melbourne School of Design \\ University of Melbourne
}

\begin{abstract}
Discussions of urban density have long been central to theories relating urban form to city life. Both maximum and minimum measures of density have been linked to qualitative aspects of cities including health, safety, creativity, vitality and sustainability. Extensive research has produced a multiplicity of density concepts: densities of building height, bulk and floorspace; densities of dwellings, people and jobs measured and perceived densities; interior and exterior; net and gross. From these are derived various density controls: floor area ratios, building envelopes, coverage and open space ratios. Despite research and practice of this kind, the modelling of interconnections between different concepts and measures has proven difficult. This paper proposes an integrative approach towards conceptualising urban density that seeks to clarify and to link key concepts within a loose framework of assemblage theory. In this model three fields of density measures buildings, populations and open space - are integrated and related to questions of scale and urban intensity. Examples of informal, suburban, urban and high-rise and informal morphologies are modelled to show how different profiles emerge according to different density measures. The model provides a basis for re-thinking density as a multiplicitous assemblage and in a manner applicable to any urban morphology.
\end{abstract}

\section{INTRODUCTION}

Urban density has long been defined and measured in a variety of ways yet without the emergence of shared definitions or measures. If one thing is clear it is that urban densities are at once social and physical; and that densities of people and buildings are not easily separated. Regulating urban density as a means of establishing and protecting urban amenity has long been standard practice for urban planning although the particular controls used are many. Amenities that are ostensibly mediated by limiting density include open space, sunlight, traffic, overcrowding, infrastructure load and public safety; those ostensibly mediated by minimum densities include streetlife vitality, walkability, public transport efficiency, environmental performance, public safety, social interaction, creativity and economic performance. The larger questions about the effects of different densities on urban life are beyond the scope of this paper which has a particular goal - to clarify a range of definitions of urban density, to build a model showing how they are related to each other, and to ground this model in a set of examples. We will first briefly explore the range of urban density definitions - densities of buildings, populations and open space - while demonstrating key linkages between them. The complexities of this model are then explored through a critique of the scale of analysis and ways of relating density to urban intensity. This model is then grounded in a set of morphological examples: suburban, urban, high-rise and informal. We demonstrate that different density measures deliver vastly different results in different morphologies - that no single measure can stand for the phenomenon of density.

We argue that a global urban design and planning practice entails stripping the density critique of its purely Western categories in order to enable comparisons between formal cities of the West and informal urbanism of the global South. We suggest that density can be re-thought in terms of a multiplicitous assemblage of definitions and controls. 


\section{DEFINING DENSITY}

The concept of density derives originally from physics as a quantity of mass per unit volume. As applied within urban studies density applies to certain quantities per unit area. These quantities can be floor space, building volumes, dwellings or people; the scale can range from a small lot to a region. The most commonly used density measure in architecture and planning is Floor Area Ratio (also known as Plot Ratio and Floor Space Index) - the ratio of total floor area to site area. Measures of 'dwelling density' (dwellings/hectare), 'residential density' (residents/hectare) and 'job density' (jobs/hectare) are widely used in human geography and planning. All of these measures may be either net or gross: net density being calculated within a development site and gross density incorporating the broader network of public space. There is also a widely understood distinction between the 'external density' at neighbourhood scale and the 'internal density' of people per room or square metre. All these conceptions of density are quantifiable and collectively referred to as 'measured density', as distinguished from 'perceived density' which has been a focus of environmental psychology and the analysis of perceptions of crowding (Bechtel \& Churchman 2002). Research on the mental health effects of density has long established that there are no correlations between mental health and urban density at neighbourhood scale (Mitchell 1971; Cohen and Sherrod 1978). While an internal density of over three persons per room is defined by the UN as a slum (United Nations 2003), the level of stress resulting from high internal densities is also mediated by local expectations and capacities for adaptation (Rapoport 1975).

In sociology the earliest discussions of density stem from Durkheim's notion of 'dynamic density' as a concentration of socially meaningful relationships (Roskamm 2011). Sennett (1970) has used the phrase 'visual density' to refer to a perceptible level of social diversity and recent German sociology incorporates the concept of 'interaction density' (Interaktionsdichte) (Häusserman 2007). In economics, conceptions of density were the foundation for Marshall's (1890) case for the economic advantages of industry concentrations - beyond a shortening of distances he suggested something 'in the air', an urban 'atmosphere' that cannot be quantified but is argued to generate spillovers of knowledge between different industries and fields. The advantages of density for learning environments was picked up by Jacobs (1969) and has developed as a theory of urban 'buzz' that is argued to characterize creative clusters (Currid \& Williams 2010; Storper \& Venables 2004). Such conceptions of density are close to another concept from physics, that of 'intensity', which describes the amount of energy flowing through an area over a period of time. The distinction between the terms density and intensity has been essential in assemblage theory (Deleuze and Guattari 1988; De Landa 2006) and has also been invoked in urban design as a complex interplay between concentrations of buildings, people and activities (Shelton et al 2011).

A range of measures of building density have been used in urban design and planning. In the 1860 s Cerdá argued for a coverage ratio of $50 \%$ with no height restriction (Soria y Puig 1999). Unwin (1909) argued for limits on coverage and dwellings per acre in order to allow flexibility of built form while controlling population density (Unwin 1909). Gropius (1931) argued for floor area ratio (FAR) controls in order to permit experimentations with new building typologies, a tradition that can be seen in popular current work such as the book FARMAX (Maas et al, 1998).

There have been a number of attempts to survey the range of density definitions with the aim to list and clarify definitions of density (Cheng 2010; Boyko \& Cooper 2011). The typical list would include: floor area ratio, dwelling density, people density, residential density, job density, net density, gross density, physical density, measured density, perceived density, internal density, spatial density and social density. These studies provide a good picture of the bewildering number of definitions of density and their inconsistent usage. They are, however, generally limited to the anglosphere and to measurable and spatial (rather than social) densities. Particularly prolific in the past decade has been the publication of catalogues of urban development types correlating built form outcomes with density measures (Fernandez Per et al, 2007; Lampugnani et al 2007; Boeijenga \& Mensik 2008; City of Vienna 2011; ). 
The range of existing research on density is broad and we are unable to cover it here, beyond demonstrating the very large number of definitions of density together with an inconsistency of naming and usage in urban design and planning. In all of this work there have been few attempts to compare different conceptions and measures of urban density and integrate them within urban theory. An early example is Jacobs (1961) who discusses relationship between residential, internal and streetlife densities. For Jacobs density is one of four key conditions for urban diversity - she argued for residential densities of about 250 dwellings per hectare as part of a larger scheme incorporating mixed-use, permeability and small grain development. In this scheme density is a necessary (but insufficient) condition for urban vitality and safety because it enables high levels of streetlife and walkable access to diverse amenities. Jacobs was also an advocate of high levels of site coverage (80\%); in her view high-density low-rise produced greater variety than a modernist tower typology. Jacobs was also a perceptive writer on urban density rhythms and argued that it is functional mix that sustains a consistency of streetlife by mixing residents, workers and visitors in public space across a range of time zones. Such urban density rhythms at a larger scale have been explored more recently by Lampugnani who graphically illustrates the day/night rhythms produced by comparing residential and job densities (Lampugnani et al. 2007).

Pont and Haupt (2010) have developed a matrix of interrelated variables, a multivariate definition of density incorporating relations between total floor area, degrees of land coverage and network morphology. They point out a nest of co-dependent variables linking site coverage, building height and floor areas. A key point of this matrix is to demonstrate the lack of direct relationship between the density of buildings and residential populations due to variability in household size, dwelling size and the proportion of non-dwelling uses (Pont \& Haupt 2010: 85). As part of their analysis they have suggested the measure of an 'urban footprint' as the total amount of floor space per resident in a given area. This footprint has increased substantially over time and can be linked to both general wealth and carbon footprints. Pont and Haupt also introduce the concept of 'network density' as a measure of network interconnectivity that is largely synonymous with permeability. They conclude with a model of a 'space matrix' wherein the key density variables are Floor Area Ratio, Coverage and Network Density.

Patel (2011) constructs a model that connects six primary density measures as follows. First he relates Floor Area Ratio to population density (people/hectare) through the measure of total floor area/capita (Pont \& Haupts urban footprint). These measures are then linked to those of open space through a concept he calls the 'plot factor': the ratio of private to public land use. This is then used to measure public space/capita (including streets and parks) as a predictor of external crowding. A net measure of people/hectare is derived from population/buildable plots. These six parameters are then mapped in a complex chart showing how change to any of them affects all the others in a direct and measureable manner. He uses this model to compare Upper East Side Manhattan with a district in Mumbai and shows that population densities in two-storey slums can be far higher than those in high-rise districts where the FAR is many times higher. He also reinforces the principle that building and population densities, while related, cannot be used to predict each other. He further argues that attempts to relieve internal overcrowding in slums by raising the Floor Area Ratio can both fail in this goal and exacerbate overcrowding on the streets.

\section{MODELLING DENSITIES}

In this paper we seek a way of unravelling this complex nest of factors one step at a time through a set of five key lenses or frameworks of analysis: Buildings, Populations, Open Space, Scales and Intensities. We begin with the building densities produced by any particular urban morphology; we then move to population densities - both interior and exterior densities of residents, jobs and visitors. Built and population densities are then linked to measures of open space and streetlife densities. The model is then analysed according to the criterion of scale - how do density measures change between gross and net measures? Finally we ask how all of these measures are related to the experiences of spaciousness, crowding and urban intensity. A key here is the 
intensity of network interconnections through which people gain access to buildings, open spaces and each other.

Our goal is to develop a model that enables us to research questions of density and urban intensity in any urban morphology, particularly to be able to contrast cities of the global north and south, and luxury housing with slums. The diagrams that follow model the interconnection between a complex range of variables. Measures of density are represented by colour-coded boxes. When one variable is derived from another this is represented by an arrow; when two variables are mediated by a third this is represented by a double arrow.

\section{Buildings}

We begin with the fact that most buildings sit vertically on a roughly horizontal 'site area' occupying a certain 'footprint' - the black/grey base of the diagram. The total 'floor area' within that site is then mediated by the number of floors represented as 'height'. These simple measures are locked into the relations represented in Figure 1 which also shows two key ratios that are commonly derived from them: 'coverage' (footprint/site area) and 'floor area ratio' (floor area/site area). While we note the crucial distinction between gross and net density measures - the question of whether or not one includes streets and public space - we will defer such discussion to the later section on scale. For now we wish to flag this basic relationship between floor area ratio, building footprint and total floor area as mediated by building height. There are clearly exceptions to such a relationship since not all floor area is above ground and not all buildings have a clear footprint and vertical walls, yet such a relation broadly prevails in a very high percentage of buildings in most cities. Buildings that lean and span across ground space remain subject to the same general principle. This diagram shows that densities are mediated by, but do not derive from, building height which is a poor predictor of total floor area because it depends on the footprint.

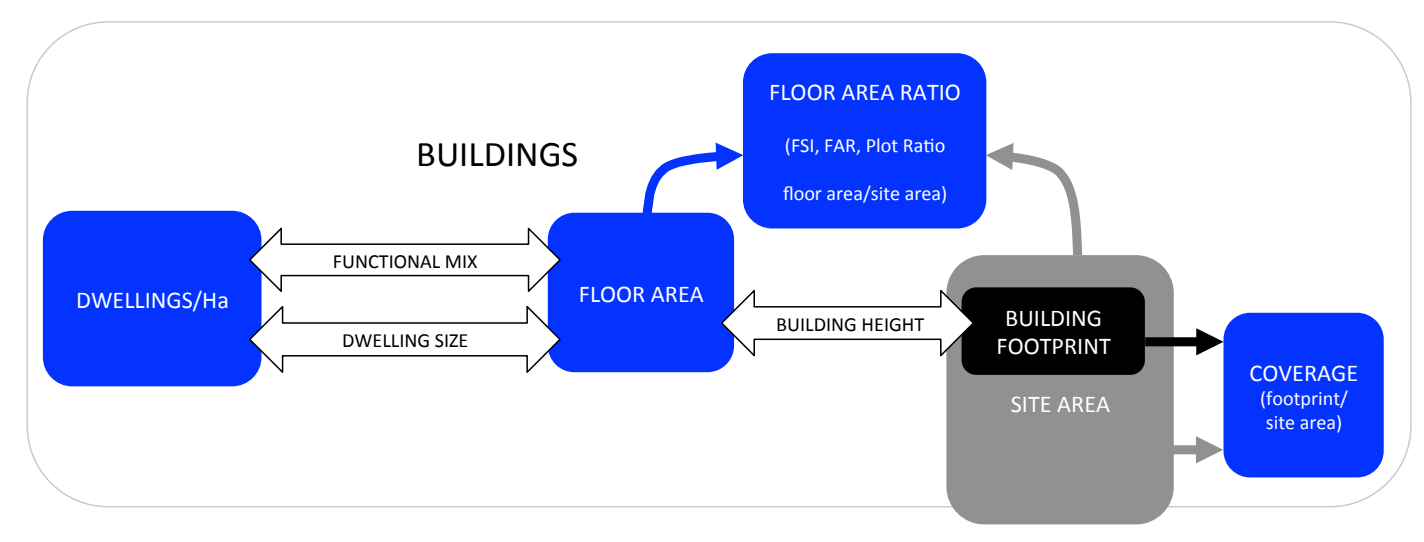

Figure 1: Building densities

We now want to connect these measures to housing densities where the most common measure of dwellings/hectare is linked to total floor space but mediated by both the proportion that housing forms of the functional mix on that site and by the average dwelling size (Figure 1). Thus a very dense area may have a low dwelling density due to housing being a marginal part of the functional mix; likewise limited floor space can be linked to large numbers of very small dwellings as in many slums.

\section{Populations}

We now move to the diagram in Figure 2 which adds a set of variables and measures on population densities. Here we find the two key measures most commonly used are residents/hectare and jobs/hectare. These figures, together with those for visitors (if available) can be used to predict total population densities together with diurnal, weekly and seasonal rhythms. We now seek to relate these population densities (marked in red) to the building densities (marked in blue) (Figure 2). The relation between dwellings/hectare and residents/hectare is mediated by the 
average household size. The two key variables that connect building and population densities are marked in purple. Internal density is derived from dwellings/hectare and residents/hectare as mediated by average dwelling size (sq $\mathrm{m} /$ resident or residents/room) - a key indicator of both slums and luxury housing. The global measure of what Pont \& Haupt call the 'Urban Footprint' (total floor space/resident) is derived from floor area and residents per hectare; it is not to be confused with either 'building footprint' or 'internal density'. In Figure 2 we now have a diagram that models the key measures of both population and building density and their relations with each other.

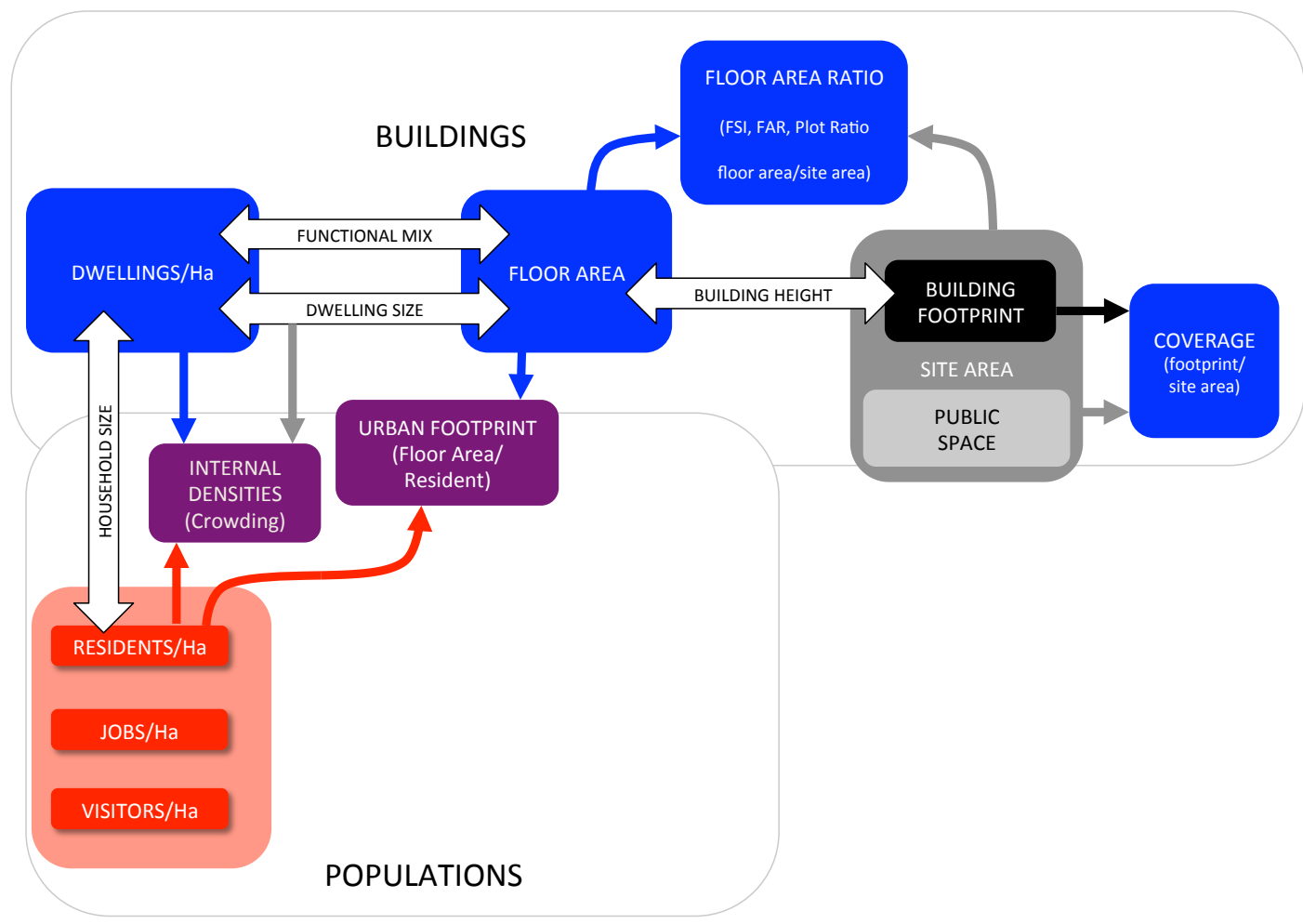

Figure 2: Relating Population Densities to Building Densities

\section{Open Space}

Densities of buildings and people are incomplete without understanding the relations of buildings to open space and the ways external densities are produced in public space. The concept of site 'coverage' (footprint/site area) is a common measure of density, generally expressed as a percentage. There are, however, other measures of open space marked in green on Figure 3. What is often referred to as the 'open space ratio' (Pont \& Haupt 2010) measures the ratio of total open space to total floor area. This is a global indicator of the way increased floor space adds pressure on unbuilt space for both circulation and recreation, but it does not distinguish between private and public open space. What Patel (2011) calls the 'plot factor' is the ratio of buildable plots to the total site, roughly a ratio of private to public space. Neither 'open space ratio' nor 'plot factor', however, connect directly to population densities; to measure density in public space requires a means to measure 'public space/person'.

Here we move to the yellow variables in the overlap between population and open space densities. Such measures, however, are deeply problematic for two reasons. First, not all unbuilt or public space is accessible or useful and much of it is consumed by vehicular traffic - we need an effective typology of useful public space. Second, populations of 'visitors', 'residents' and 'jobs' cannot be simply totaled to get a total population because many of the visitors, at any one time, are replacing residents and workers who have become visitors in another place at that time due to urban 
rhythms of production, consumption, recreation, rest and travel. Any measure of 'visitors' is simply a measure of the distinction between local and global flows. The proportion of visitors will vary by functional mix, levels of employment and industry types; in locations such as dormitory suburbs, industrial zones and tourist districts the number of visitors will fall short of or exceed the replacement of residents and workers who are absent. We come then to the final measure that we might call streetlife density (marked in yellow since it joins overall population densities to open space). Such measures of density, however, are much less measureable than those we have modelled hitherto, mediated in fundamental ways by both urban rhythms and public/private interfaces (Figure 3). The interface makes a difference mostly because it is linked to car dependency - the car-based interface enables the population to live, work or visit without contributing to streetlife. Here we begin to join a circle since the density of public open space per person overlaps with measures of streetlife density.

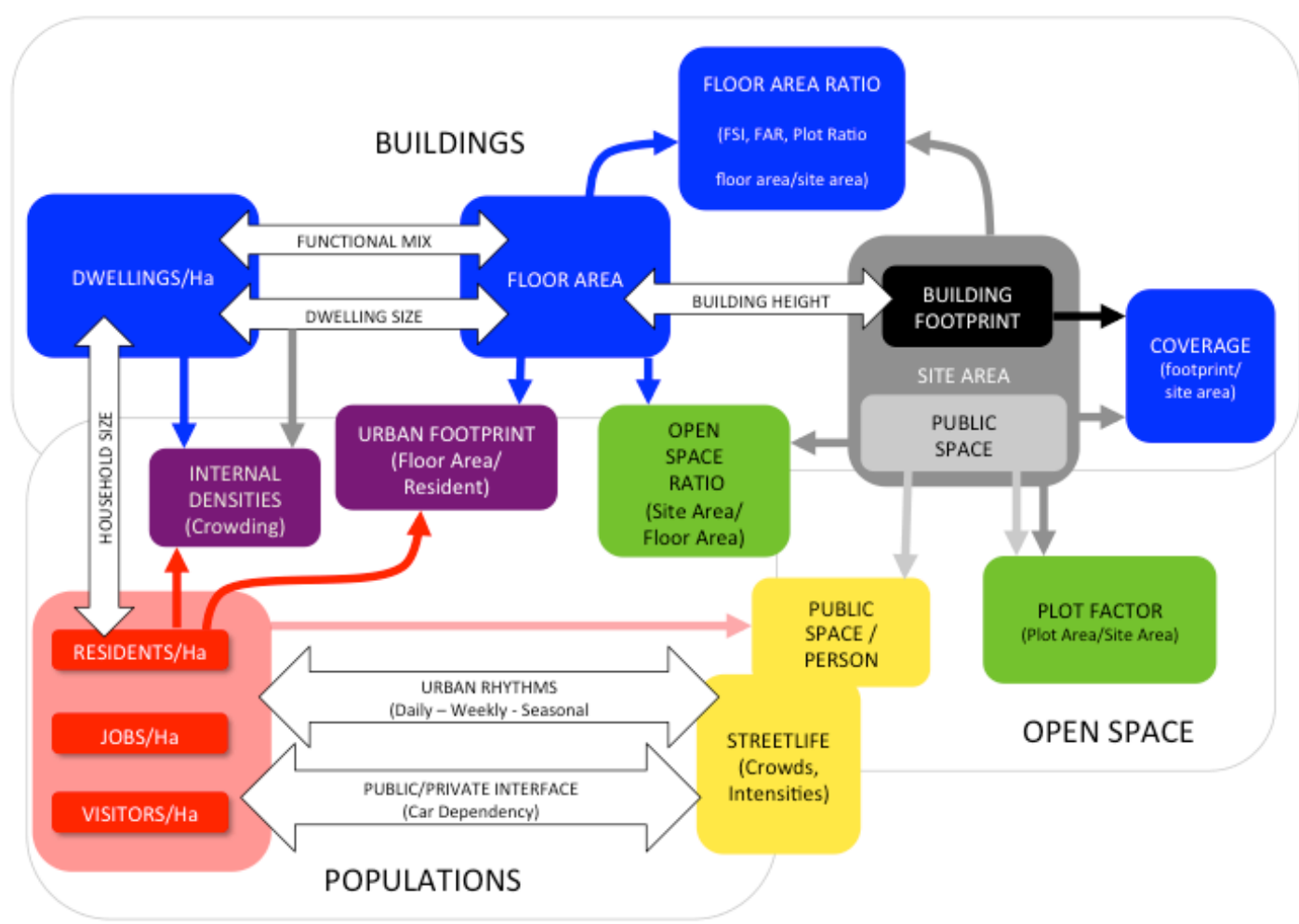

Figure 3: Relating Open Space to Buildings and Populations

All of the boxes within the diagram (with the exception of those contained on the site) are different and plausible measures of density, derived from their connections with other variables and mediated by the variables shown as double arrows. The interdependent variables within this model are all highly contingent on each other for their measurement, meaning and usefulness. The concept of density cannot be reduced to any particular part of the model and is best conceived as embodied within the assemblage of interconnected variables. This three-part model incorporating 14 different density measures and 5 mediators is highly complex; some may argue that it is too complex to be understood or to be useful. Our response is that it connects and incorporates most of the key measures that are currently being both used and confused. It enables us to see how they are connected and to make judgements about how density should be defined, measured and understood. However, it also needs to be elaborated by linking these measures to questions of scale and intensity.

\section{Scales}

Measures of density are not meaningful until one defines the territory within which such measures take place and account for the differences between net and gross densities. Net densities are 
generally measured within a particular development site or may be aggregated across all private land - they are crucial for the practice of development control. As one changes scale from the single site to the neighbourhood and district, spatial heterogeneity increases to incorporate different functions, open space, access networks and interstitial space. In other words as the scale of analysis increases the density measures go down. This is also why density measures at metropolitan scale can show LA to be denser than New York (Mees 2009). Gross densities are the primary indicators for larger scale urban outcomes such as infrastructure load, traffic and open space. The density measures diagrammed above for buildings, populations and open space must be considered in accordance with this gross/net distinction in the sense that the variables in any given analysis will be either gross or net but not both. The danger lies in confusing gross with net measures or in using one to derive the other. Jacobs famously suggested a minimum density of $\sim 250$ dwellings/hectare (100/acre) in order to produce the urban conditions she was proposing this was a net figure but because she was arguing for a gross urban outcome under conditions of mixed use it is often misunderstood.

As a framework for articulating this distinction between gross and net density, Pont \& Haupt (2010) suggest four key territories: lot, island, fabric and district. The 'lot' is the cadastre or 'plot'; the primary territory for market transactions and essentially a net measure. The 'island' is the urban 'block' comprised of multiple contiguous private properties surrounded by public space; it can be measured as net (a cluster of plots) or gross (by including half the surrounding streets). The 'fabric' incorporates a larger pattern of streets and blocks (at varying scales) where the fabric is of homogenous function and density - the measure is essentially gross. Finally, the 'district' is the larger urban area incorporating heterogeneous functions including schools, parks, shopping, transport and so on - it is essentially a gross measure. These categories derive in part from the urban morphology of Conzen with cities construed as a mutual dependence between blocks and streets, between the urban 'islands' and the access network that connects them via public/private interfaces. While such a scheme clarifies these issues in many contexts, it confuses distinctions of scale with those between gross and net measures. The distinction between gross and net is a relative rather than absolute distinction between scales. Not all urban morphologies are clearly defined into lots and islands; even when they are, the cadastre or 'lot' in one may be larger than the 'block' or 'island' in another. Is a 50 hectare gated community that incorporates traffic and open space to be considered a 'lot', 'island', 'fabric' or 'district'; are its internal densities net or gross? How can the tiny blocks and laneways lanes of an informal settlement be compared with the large blocks of an urban grid? Lot, island, fabric and district are useful as morphological categories but they are not absolute scales, and if we are to compare fundamentally different urban morphologies then we need to use absolute scales for analysis. While there are no rules for such scales, the issue of density clearly requires a multi-scale analysis that enables understanding of the relations between scales from the building to the metropolis. This double issue of net versus gross measures and the scale at which either is measured becomes crucial for public debate on key issues of urban development because the scope for misunderstanding and deception is significant.

\section{Intensities}

The measure of 'network density' introduced by Pont \& Haupt (2010) is an attempt to measure permeability - the capacity for urban interconnection via public space networks. Permeability, however is highly problematic to measure: does one measure street length (as Pont \& Haupt do), number of intersections, block area or block perimeter? And at what scale? There is no scope to pursue this important question here. In Jacobs' work, permeability ('short blocks') was considered separately from density; it is a concentration of relationships rather than buildings or people and should be termed 'network intensity' rather than a form of 'density'. Permeability is a property that bridges between measured and perceived densities, between the measured densities mapped in this model and the phenomenology of urban streetlife. Network intensity is not a part of the model outlined in Figure 3 but rather a mediator that infuses the whole. It mediates the experience of 'crowding', 'spaciousness' or 'intensity' of interaction in public space produced by building and population densities. 
If density is defined as the largely measureable degree to which built forms, jobs, residences and activities are co-located, urban 'intensity' can be defined as the experience of intensive encounter in public space that may or may not emerge under conditions of density. Intensity differs from density in being a synergistic effect that is more than the sum of parts. While density is about volumes of people, jobs, floor space and buildings, intensity is more like the 'temperature' of a city, albeit one that cannot be easily measured. Intensity is an emergent effect of the connections, alliances, interactions and differences between the people, practices and built forms that comprise the city (De Landa 2006). The relationship between density and intensity is relatively untheorized and our thoughts in this regard are speculative. We would tentatively suggest that this is an area where urban design plays a key role in mediating this relationship, particularly through the design and regulation of the public/private interface. There are clearly urban precincts which produce the phenomenon of 'density without intensity'. This is particularly the case where towers surmounting parking garages produce a blank interface with a high level of drive-in/drive-out amenity linked in turn to low levels of street amenity and walkability. We also suggest a corollary where medium densities can produce intensive streetlife. This, we suggest, is an emergent synergistic effect of a range of density measures working together - a medium density of buildings and populations with high network intensity delivering good access to attractive public spaces.

\section{EXAMPLES}

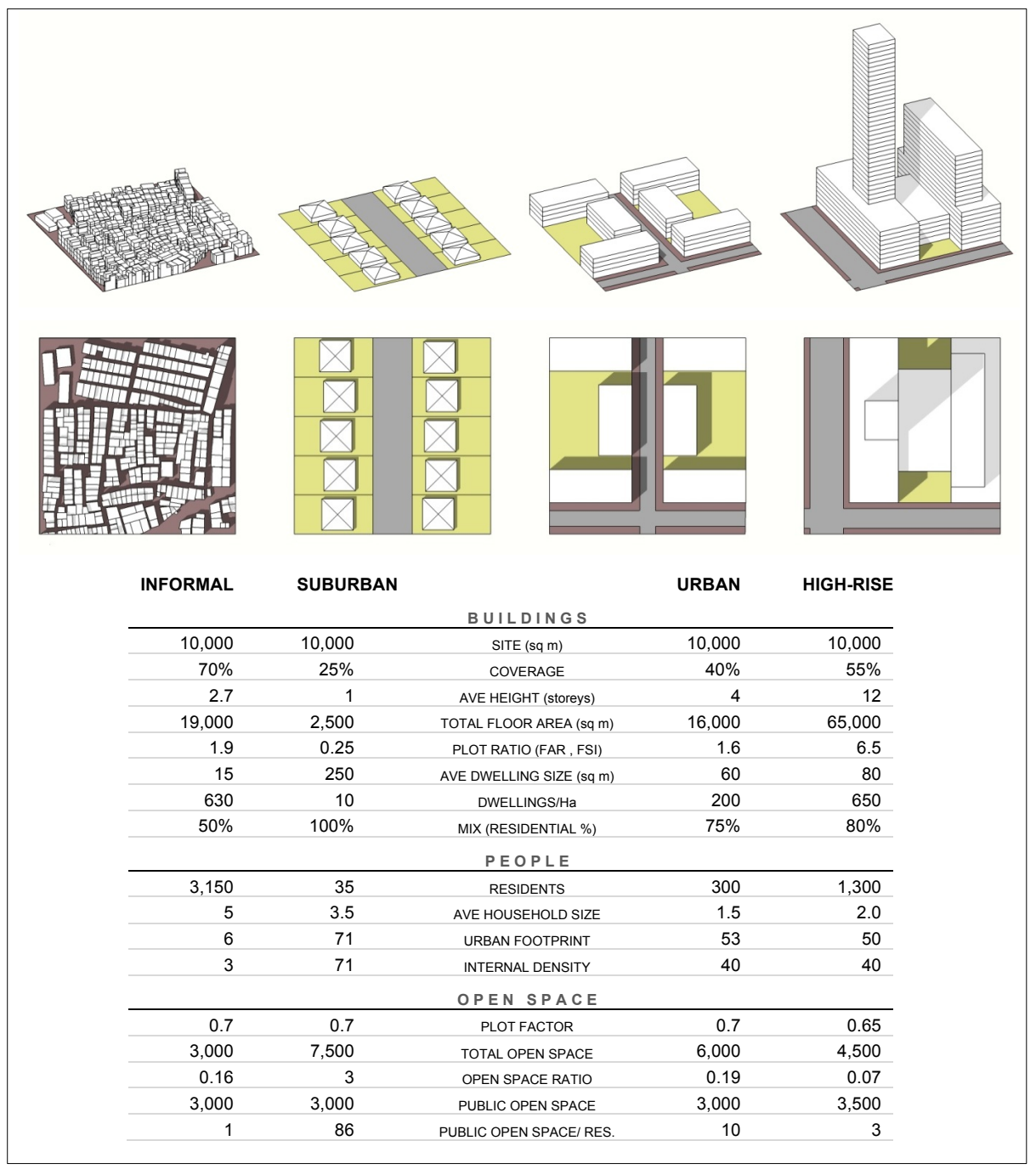

Figure 4: Calculating Densities in Four Morphologies 
We now want to ground this model in some explicit examples at an urban design scale. In Figures 4 and 5 we have modelled four very different urban conditions at a one-hectare scale - an informal settlement followed by typical suburban, urban and high-rise conditions. The suburban, urban and high-rise morphologies are based on typical conditions: suburban is single storey and monofunctional; urban averages 4 storeys with high-rise at 12 storeys. Average dwelling and household sizes are derived from the census data for New York, London and Melbourne ). There is no average data for informal settlements - the example here is based on a study undertaken in Dharavi (Bombay) in 2011 (ref). With an average dwelling size of 15 square metres and household size of 5 , the informal settlement is also a slum by UN standards. Figure 4 first shows plans and axonometric views of these four morphologies at a one-hectare scale; these are then combined with further data to list values for the variables modeled earlier. We are inspired in this endeavour by the work of Patel (2011) who has modeled similar factors comparing informal and high-rise morphologies at a larger scale using multiple measures and incorporating criteria for desirable densities. Our approach is to leave aside the normative issues at this stage and to focus on a much smaller urban design scale. One result of this comparison is that some variables differ dramatically between these examples while others do not. Morphological measures such as coverage, plot factor and public open space differ by a factor of up to three between examples; others such as average height, total floor area, floor area ratio, urban footprint and open space ratio show a much larger range and variables that include social factors of household size, dwelling size and population can differ by a factor of up to 90 .

Some of the comparative density effects have been illustrated graphically in Figure 5 - for each of the examples it shows four building densities followed by two population densities and one open space density. In each case the data from Figure 4 has been collapsed into a standard height with all values expressed as a proportion of the highest value in our examples. This graph shows that only the Suburb (brown) has any consistency of density measurement across these different measurement variables. While the High-rise forms (blue) show high building densities they vary across the other measures. The Informal settlement profile is almost the inverse of the High-Rise with lower morphological densities and higher population densities. The graph reinforces one of Patel's key points about the bluntness of floor area ratio (FAR) as a planning tool because the much higher FAR of the High-Rise does not produce any more dwellings than the slum; if FAR were ramped up to solve the slum problem without addressing other factors then external density is exacerbated. What seems like a consistency of open space density in the non-suburban examples is at least partly an effect of the contrast with extremely low suburban densities. While this graph can be difficult to read, these wild fluctuations of profile for different urban conditions reinforce the point that no one measure of density can be used to simply predict another. 


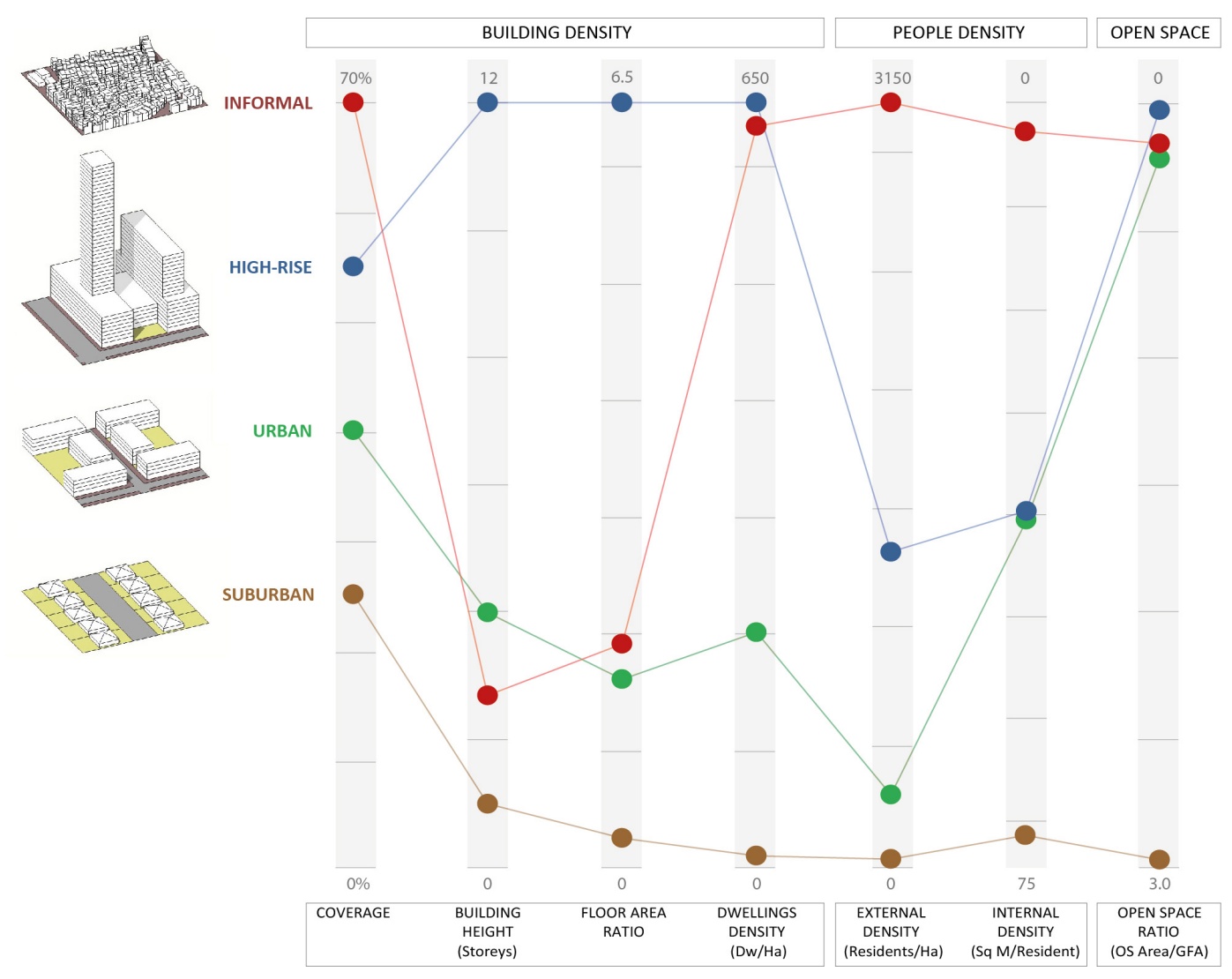

Figure 5: Comparing Morphological Profiles

\section{ASSEMBLAGES}

Having sketched out this model and tested it against examples of different morphologies at one particular scale, the question remains of how one might use such a framework for re-thinking urban density. If density can be measured in all these ways, and shown to be interconnected in all these ways, then how does that change the ways we might think about density? How might this model then be used not only in understanding cities but in changing them through urban design and planning? Scope for discussion on these questions in this paper is limited to some suggested ways of re-thinking the concept of density and opening up further questions for research.

While it is possible to see the model we have built as a form of multivariate analysis, the concept of density cannot ultimately be defined by these numbers, no matter how good our measures might become. While many of the relations between variables described above are measureable and predictable, in any real city variations of household and dwelling size, functional mix, interface and urban rhythm make densities difficult to predict or control. Furthermore, the outcomes that really matter in terms of experiences of crowding and streetlife intensity cannot be measured in these ways and inherently resist reduction to quantification.

Rather than simply choosing which measures to use we suggest that it can be useful to think of this as a 'density assemblage' with a focus on the dynamics of relationships between them. Such an approach locates this study within a framework of assemblage theory which seeks to understand the world in terms of multiple linkages between sociality and spatiality, where unpredictable outcomes emerge from alliances, connections and symbioses between parts (Deleuze \& Guattari 1987, DeLanda 2006, Dovey 2010). While the boxes in Figure 3 are the 
measureable components of the density assemblage, the ways they are assembled through the various mediators are key to overall outcomes. These mediators, such as interface type, height, functional mix, average household size and dwelling size, are in many ways the drivers of the density effects that emerge in the examples of Figure 5. These mediators are also interconnected throughout the larger assemblage; in other words the model depicted in figure 3 is already oversimplified; it is a diagram that seeks to communicate some primary ways in which the urban density assemblage works. Rather than add more arrows to an already difficult diagram we will explore some of these complexities through the lens of some of its key density variables.

Building height, as argued earlier, is a mediator rather than a simple measure of density since the links to building density depend on building footprint and coverage. Yet the role of height as a mediator is an important one since a taller building enables a greater floor area ratio and greater open space with a smaller building footprint. This was indeed one of the key dreams of modernity - that we could have it all in urban design with light, air, views and open space at high densities. As building densities rise so does the capacity for population density, dependent on household and dwelling sizes. This in turn potentially raises streetlife intensity, dependent on interface types and network density. However, greater height and intensity do not necessarily go together; height does not inevitably bring eyes and people on the street. While density was a key property in Jacobs' conception of a vibrant and vital city, she was also an opponent of tall, modernist housing projects. Building height often indirectly impacts on streetlife by imposing a separation between public and private space. The most potent impact of tall buildings on the public/private interface comes when it is combined with car-dependency. Building height also has an impact on functional mix because a high-rise building creates a cul-de-sac in the urban fabric wherein it become progressively difficult to sustain a rich functional mix. There have been many attempts to mix functions in three dimensions, yet all of the urban successes have occurred within a couple of floors of ground level - beyond which it becomes inevitably monofunctional or privatized. A rich urban functional mix remains essentially horizontal in character. Functional mix in turn has a huge impact on rhythms of everyday life which in turn mediate streetlife densities. The point here is not to argue for height controls, but for a more sophisticated way of thinking about the interconnections of height to the full range of urban design and planning variables; and for an understanding of height as a mediator rather than a direct measure of density.

The major alternative to prescribed building heights is the Floor Area Ratio (Floor Space Index, Plot Ratio). Floor Area Ratio is an attractive density control that can be used to contain overall development volumes without limiting urban design outcomes - it allows freedom for urban innovation. Floor Area Ratio is also attractive because it is so strongly geared to flows of capital. The yield of any building project in square metres of usable floorspace is the key component of any cost benefit analysis and (depending on demand) a higher Floor Area Ratio delivers a greater profit. Floor Area Ratio is attractive to market-driven planning because it can be used to increase profitability. The key problem is that it does not necessarily create or protect urban amenity - the connection to height is very loose and it has no connection whatever to functional mix, dwelling size, population, public/private interface, urban rhythms or open space. As a planning control it does not impact with any depth on the density assemblage. The power of Floor Area Ratio lies in its economic base and potential for innovation, however, any reduction of density thinking to such a single measure is dangerous; it is a very blunt urban planning tool that enables and constrains floorspace and profit, but cannot by itself directly protect nor create urban amenity.

Site coverage is a similarly shallow measure in that its effects do not penetrate deeply and broadly across the density assemblage. As a planning control coverage is generally used as a maximum to prevent perceived overdevelopment of a site and to protect private open space; it has little relation with population densities, mix, rhythm or interface. Jacobs proposed high levels of coverage because this is the effect of building density without height, however, coverage can only control density when combined with other controls such as height or floor area ratio. 
None of these measures has any direct impact on population densities; the key measure historically deployed in this regard has been dwellings/hectare. As the model demonstrates, this is also a very blunt control unless we also know something of the dwelling size, household size and functional mix. Dwelling size is generally only regulated as a minimum and it is impossible to legislate household size, yet the issue of population density makes little sense if these measures are not considered. Jacobs advocated a density of about 250-500 dwellings/hectare (net) - over 25 times a suburban density - as a means of establishing sufficient urban density. It is difficult, however, to understand the rationale for these figures Glaeser (2011) has recently argued that Jacobs' figure is too low for effective urbanization but again there is little rationale for such a position.

Considerable scope for development of density research lies in the field of urban open space and questions of how the public space infrastructure of the city enables and constrains densities of public life. This is the final (yellow) part of the model in figure 3 and it requires that we develop a better model of what constitutes useful and accessible public space, and how it can be played off against private open space. Current measures of open space, such as open space ratio (site area/floor area) and plot factor (private/public land area), are very blunt. Measures of effective or useful public open space/person are contingent on measures of public versus private open space on the one hand, and on levels of vehicular space, access and functional mix on the other. A meaningful measure of public open space density further relies on the development of a clear and mappable typology of public space types - the typology developed by Carmona (2010) might be a beginning.

We will conclude with four general points about re-thinking the concept of density and applying density controls. First is that any approach needs to be anti-reductionist. Urban density is not a property of buildings or people but of spatial relations between them; between buildings, between people and also between people and buildings. The multiplying complexities here make it clear that no single density measure or variable can be considered apart from the larger assemblage; and each of these measures needs to be seen as mediated by height, interface, mix, grain-size and rhythm. While the relations between particular density measures may be systematic, the significant emergent outcomes are not so predictable. It is a mistake to treat density as one thing when it is a multiplicity; it is a mistake to see density in terms of building, people or open spaces when it is a set of conjunctions between them.

Second, it follows that a focus on any single density control is similarly fraught. Urban design and planning controls such as height, floor area ratio, dwelling density and setback can all be useful in different circumstances and can be applied as minimum, maximum or both. Different controls may be combined to achieve particular effects; for instance a minimum of dwellings/hectare can be combined with a maximum height or floor area ratio and functional mix to produce an average dwelling size. Proponents of using simple density controls either to produce intensities or to solve problems of crowding may be misconstruing the ways in which the density assemblage works.

Third, a point that has been made before but not well-learned: density is multi-scalar with different measures and effects operating at different scales. The question of urban density makes little sense before one defines the scale. Vastly different measures occur at different scales of the room, street, neighbourhood, district and metropolis. The contrasts we demonstrate between different measures in Figure 5 make sense only at the scale of one hectare. Density measures at one scale can be misapplied at another; our thinking about density needs to become fundamentally multiscalar.

Finally, we suggest more attention be paid to the somewhat mysterious relation of density to urban intensity. Depending on how urban design controls in particular are managed, we can produce density without intensity or intensity without high density. There are many kinds of urban intensity and while all depend on certain levels of density, intensity is not a phenomenon that simply increases with building or population densities. This is the next step in the 'life and death of great 
cities' narrative initiated by Jacobs so long ago. While her analysis was ostensibly about American cities it has proven broadly applicable; we now need models that apply also to Asian and informal cities. The mystery, however, will remain because density controls are mere formulae and the urban intensities of great cities are somewhat more elusive. With apologies to Tolstoy one might say: boring cities are all alike, every great city is great in its own way.

\section{BIBLIOGRAPHY}

Alexander, E. (1993) Density Measures: A Review and Analysis. Journal of Architecture and Planning Research 10(2): 181-199.

Bechtel, R. and Churchman, A. (2002) Handbook of Environmental Psychology. New York: Wiley. Boeijenga, J. and J. Mensik (2008) Vinex Atlas. Rotterdam: 010 Publishers.

Boyko, C. T. and Cooper, R. (2011) Clarifying and re-conceptualising density. Progress in Planning (76). pp. 1-61

Carmona, M. (2010) Contemporary Public Space, Part Two: Classification. Journal of Urban Design, 15(2): 157-173.

Cheng, V. (2010) Understanding Density and High Density. In: Ng, E. (ed.) Designing high-density Cities for Social and Environmental Sustainability. London: Earthscan, pp. 3-18.

Churchman, A. (1999) Disentangling the Concept of Density. Journal of Planning Literature,13(4): 389-411

City of Vienna and Bratislava Magistrate (2011) Patterns for New Urban Developments. Vienna.

Cohen, S. and Sherrod, D. (1978) 'When Density Matters'. Journal of Population, 1(3), 189-202.

Currid, E. and Williams, S. (2010) The Geography of Buzz. Journal of Economic Geography, 10, 423-451.

DeLanda, M. (2006) A New Philosophy of Society, New York: Continuum.

Deleuze, G. and Guattari, F. (1987) A Thousand Plateaus. London: Athlone.

Dovey, K. (2010) Becoming Places. New York: Routledge.

Fernández Per, A., Arpa, J. and Mozas, J. (2007). DBook: Density, Data, Diagrams, Dwellings, Madrid: a+t ediciones.

Glaeser, E. (2011) Triumph of the City. London: Pan.

Gropius, W. (1931) Flach-, Mittel- oder Hochbau? Schweizerische Bauzeitung_(97/98): 95-100.

Häusserman, H. (2007) Phänomenologie und Struktur städtischer Dichte. In: V. Lampugnani, T. Keller and B. Buser (eds.) Städtische Dichte. Zurich:. Nzz Libro. pp.19-30

Jacobs, J. (1961) The Death and Life of Great American Cities. New York : Random House.

Jacobs, J. (1969) The Economy of Cities. New York: Vintage.

Lampugnani, V., Keller, T. and Buser, B. (eds.) (2007) Städtische Dichte: Urbanisierungsstrategien für die Schweiz. Zurich: Nzz Libro.

Maas, W., v. Rijs, J. and Koek, R. (1998) FARMAX: Excursions on Density. Rotterdam: 010 Publishers.

Marshall, A. (1890) Principles of Economics. London: MacMillan.

Mees, P. (2009) Transport for suburbia: beyond the automobile age. London: Earthscan.

Mitchell, R. E. (1971) Some Social Implications of High Density Housing. American Sociological Review 36(1): 18-29

Patel, S. (2011) Analyzing Urban Layouts: Can high density be achieved with good living conditions? Environment \& Urbanization, 23(2): 583-595.

Pont, M. and Haupt, P. (2010) Spacematrix: Space, Density and Urban Form. Rotterdam: NAi. Rapoport, A. (1975) Toward a Redefinition of Density. Environment and Behavior 7(2): 133-158.

Roskamm, N. (2012) The Concept of Density. Graz Architektur Magazin (GAM) (08 Dense Cities: Architecture for Living Closer Together): 130-141.

Sennett, R. (1970) The Uses of Disorder: Personal identity and city life. New York: Knopf.

Shelton, B., Karakiewicz, J. and Kvan, T. (2011) The Making of Hong Kong, London: Routledge.

Sherrod, D. R. and S. Cohen (1982) Density, Personal Control, and Design. In: S. Kaplan and R. Kaplan (eds.) Humanscape: Environments for people. Ann Arbor: Ulrich's Books. pp.189202 
Soria y Puig, A. (ed.) (1999) Cerdá : The Five Bases of the General Theory of Urbanization. Barcelona: Electra.

Storper, M. and Venables, A. (2004) Buzz: Face to Face Contact and the Urban Economy. Journal of Economic Geography, 4(4): 351-370.

United Nations (2003) The Challenge of Slums. London: Earthscan.

Unwin, R. (1909) Town Planning in Practice. An Introduction to the Art of Designing Cities and Suburbs. London. 